\title{
XY Female: Two Cases with Different Gonads presenting as Primary Amenorrhea
}

\author{
Badekai Poornima Ramachandra Bhat, H Mahesha Navada
}

\section{ABSTRACT}

Two 18-year-old female patients admitted to the hospital with the complaints of primary amenorrhea. The clinical examination and investigations revealed one of them as complete androgen insensitivity syndrome and the other Swyer syndrome. Bilateral gonadectomy was performed and hormone replacement therapy started for both the patients. These two conditions should be considered in the differential diagnosis in every adolescent female patient with delayed puberty and the importance of early gonadectomy should be stressed in order to avoid the risk of gonadal tumor development.

Keywords: Complete androgen insensitivity syndrome, Swyer syndrome, Primary amenorrhea, Gonadectomy.

How to cite this article: Bhat BPR, Navada HM. XY Female: Two Cases with Different Gonads presenting as Primary Amenorrhea. World J Endocr Surg 2012;4(1):23-25.

\section{Source of support: Nil}

Conflict of interest: This is to certify that I, Badekai Poornima Ramachandra Bhat, the author of ' $X Y$ Female: Two Cases with Different Gonads presenting as Primary Amenorrhea' certify that there is no conflict of interest regarding the publication of this manuscript.

\section{INTRODUCTION}

$\mathrm{XY}$ female is a intersex condition who has a chromosome composition of $46 \mathrm{XY}$ and female phenotype. They may present in a variety of ways. It is the absence of testicular androgens or antimullerian hormone production or an inability of the body to respond to these hormones that cause female phenotype to occur in XY females. These conditions are relatively rare and can be difficult to diagnose accurately and manage appropriately. Androgen insensitivity syndrome (AIS) is the most common cause of $\mathrm{XY}$ female and the incidence is probably around 1 in 40,000 to 60,000 births. ${ }^{1}$ Complete androgen insensitivity syndrome (CAIS) occurs when there is no response to androgens. Partial androgen insensitive syndrome occurs when the androgen receptors can partially respond to androgen stimulation. Swyer syndrome is the other rare cause of XY female and the incidence is 1 in 1,00,000 births. ${ }^{2}$ Swyer syndrome also known as pure gonadal dysgenesis was first described by Gim swyer, a London-based endocrinologist in 1955. There is testicular differentiation abnormality in Swyer syndrome. We are reporting cases of both these syndromes each showing different gonadal tissue presenting as primary amenorrhea.

\section{CASE REPORTS}

\section{Case 1}

An 18-year-old unmarried girl came with complaint of primary amenorrhea. She had three sisters. Elder sister who was 21-year-old and her maternal aunt both have not attained menarche. They were not investigated. Other two sisters attained menarche at the age of 16 . She was $152 \mathrm{~cm}$ tall and weighed $58 \mathrm{~kg}$ on examination. Breast development was tanner stage 3. Axillary and pubic hairs were absent. Abdominal examination was normal. Local examination revealed normal female external genitalia with blindly ending vagina. Buccal smear did not show barr bodies. Ultrasound abdomen showed absent uterus with hypoechoic structures in relation to iliac vessels suggestive of gonads (Fig. 1). Chromosome analysis by $\mathrm{G}$ banding showed $46 \mathrm{XY}$. Bilateral gonadectomy was performed through the inguinal incision (Fig. 2). Histopathology of right gonadal mass showed sertoli cell adenoma and left gonadal mass showed sertoli cell hyperplasia. Patient was advised estradiol valerate $2 \mathrm{mg}$ daily as hormone replacement therapy (HRT).

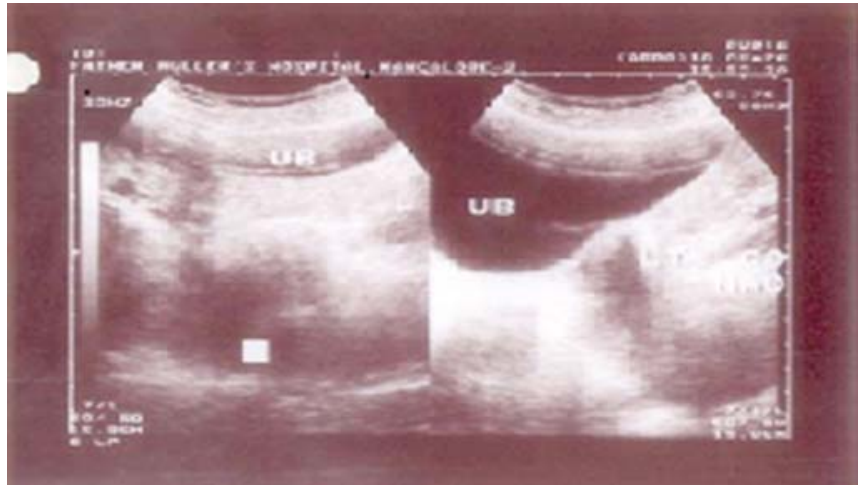

Fig. 1: Transabdominal ultrasound gonad near the iliac vessels

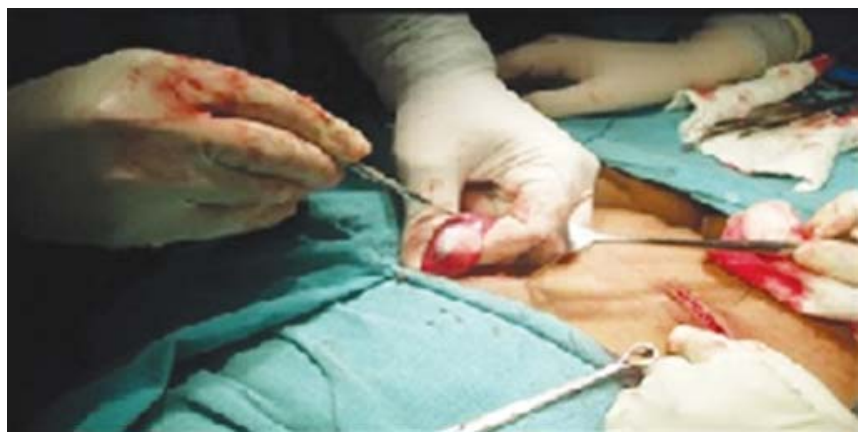

Fig. 2: Bilateral gonadectomy 


\section{Case 2}

An 18-year-old female came with complaints of primary amenorrhea and no breast development. There was no family history of similar complaints. She was $162 \mathrm{~cm}$ height and $48 \mathrm{~kg}$ weight. Her breast examination showed tanner stage 1 . The axillary and pubic hairs were sparse. Abdominal examination was normal. The external genitalia appeared normal female type with normal vagina. Ultrasound revealed hypoplastic uterus $30 \times 9 \mathrm{~mm}$, right ovary $21 \times 8 \mathrm{~mm}$ and left ovary $18 \times 8 \mathrm{~mm}$. Serum follicle stimulating hormone (FSH)—70.80 IU/ml (high), luteinizing hormone (LH)$31.61 \mathrm{IU} / \mathrm{ml}$ (high), serum prolactin—5.21 ng/ml (normal) serum estradiol (E2)—13.47 pg/ml (low). The chromosomal analysis showed $46 \mathrm{XY}$ karyotype (Fig. 3). This was confirmed by two laboratories. Laparoscopic bilateral gonadectomy was performed. Histopathological examination was bilateral ovarian stroma with congested blood vessels and adipose tissue (Fig. 4). Subsequently, she was started on HRT with both estrogen and cyclical progesterone. She had menarche and her height and weight were increased to $166 \mathrm{~cm}$ and $53 \mathrm{~kg}$ respectively, with marginal breast development on follow-up.

\section{DISCUSSION}

$\mathrm{XY}$ females have male genotype $46 \mathrm{XY}$ with varied female phenotype ranging from female external genitalia to that with some features of virilism. XY female can be due to a variety of genetic defects that affect hormone-dependent formation of the male external genitalia. Sexual differentiation follows a sequential pattern in utero. After fertilization, there is establishment of the genotype of the embryo and the primordial gonads differentiate into ovaries

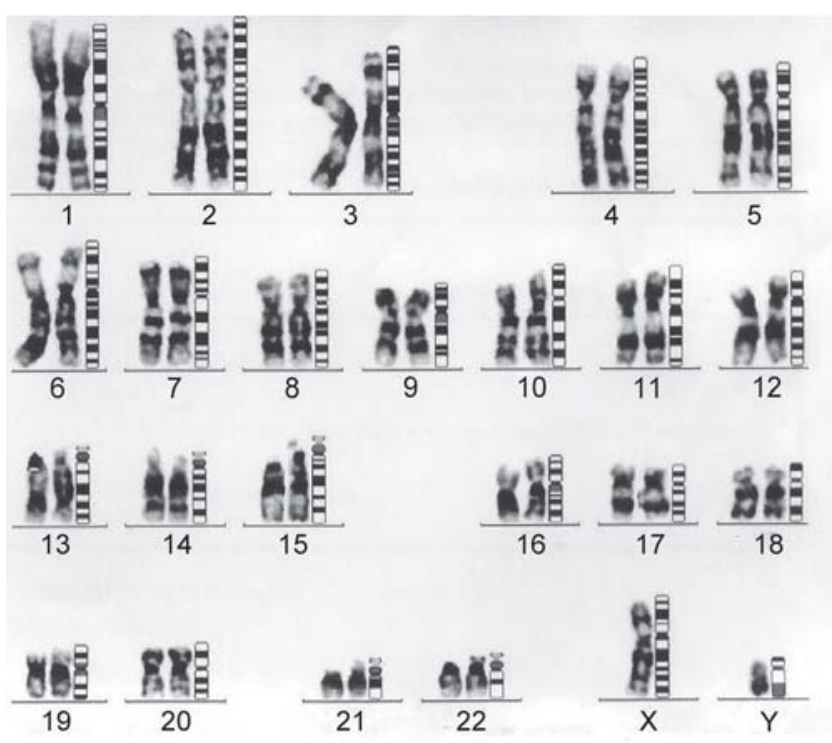

Fig. 3: Karyotype with $46 \mathrm{XY}$

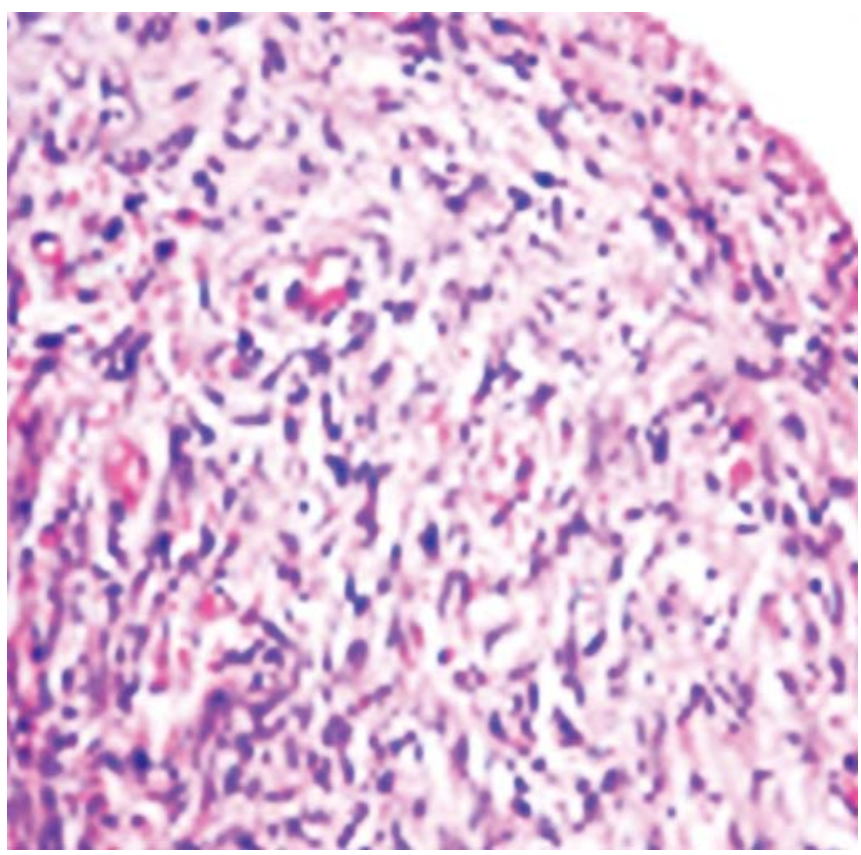

Fig. 4: Ovarian stroma $(40 \times \mathrm{H} \& \mathrm{E})$

by default in the absence or nonfunctioning of the $\mathrm{Y}$ chromosome. Under the influence of the single gene determinant (testes determining factor) on the short arm of the $\mathrm{Y}$ chromosome, they differentiate to testes. This differentiation of the primordial gonads into the testes or ovary will lead to an alteration of the hormonal milieu of the fetus, which in turn results in the corresponding differentiation of the internal and external genitalia. The external genitalia also develops into female external genitalia by default in the absence of effective male sex hormones.

In our first case, we made the diagnosis of CAIS as she presented with primary amenorrhea with underdeveloped female external genitalia, better developed breast, absence of pubic, axillary hairs and uterus. The most important is the presence of testis instead of ovaries with XY karyotype. This X-linked inherited disease is the result of absent or qualitative or quantitative abnormalities of androgen receptors. ${ }^{3}$ The gene is located in the q11-12 region of $\mathrm{Y}$ chromosome. ${ }^{4}$ Detection of AIS demands careful investigations of other affected family members, since it may also occur in other family members.

Our second patient was a female with normal stature, presented with primary amenorrhea, sexual infantilism, hypoplastic uterus, with pure XY genotype and the gonadal tissue showing the features of ovarian stromal tissue. Hence, the diagnosis of Swyer syndrome was made. The main differential diagnosis of Swyer syndrome is mixed gonadal dysgenesis which is more frequently seen than the former. In this condition, the gonads on histopathology will also show testicular differentiation. 
The etiology of this $46 \mathrm{XY}$ gonadal dysgenesis is thought to be a short arm Y chromosome deletion involving sex determining region of $\mathrm{Y}$ chromosome (SRY), a mutation in other genes that leads to inhibition of SRY function or mutation of SRY function. ${ }^{5}$ These inhibit testicular differentiation and inhibit antimullerian hormone production.

Management of XY female involves the following:

i. Making the correct diagnosis.

ii. Communicating the diagnosis to the patient and the parents along with expert psychological support.

iii. Need of early gonadectomy since the risk of malignancy is 5 to $10 \%$ in childhood rising to $30 \%$ by the age of 50 years. ${ }^{6}$

iv. Lifelong HRT is essential after gonadectomy for many aspects of health and well being which may include induction of puberty and to maintain bone mineral density. Presence of uterus in Swyer syndrome requires cyclical HRT with progesterone to induce menstruation.

v. Treatment for vaginal hypoplasia may be required in these XY females to have coital function.

vi. Females with Swyer syndrome are able to conceive with in vitro fertilization and donor oocyte. ${ }^{7}$

\section{CONCLUSION}

Early diagnosis and prompt follow-up is important for the risk of gonadal malignancy and for the adequate HRT to improve bone mineral density.

\section{REFERENCES}

1. Quigley CA, De Bellis A, Marschke KB, et al. Androgen receptor defects: Historical, clinical and molecular perspectives. Endocr Rev 1995;16:271-321.

2. Vollrath D, Foote S, Hilton A, et al. The human Y chromosome Swyer GIM. Male pseudohermaphroditism: A hitherto underscriebed form. Br Med 1995;2:709-12.

3. Hughes IA, Evans BAJ. Androgen insensitivity in 49 patients: Classification based on clinical and androgen receptor phenotypes. Horm Res 1987;28:25-29.

4. Brown CJ, Goss SJ, Lubahn DB, et al. Androgen receptor locus on the human $\mathrm{X}$ chromosome: Regional localization to $\mathrm{Xq}$ 11-12 and description of DNA polymorphism. Am J Hum Genet 1989;44:264-69.

5. Speroff L, Feritz MA. Clinical gynecologic endocrinology and infertility (7th ed) 2005;322-25, 348-49, 386-87.

6. Manuel M, Katayama PK, Jones Jr Hw. The age of occurrence of gonadal tumours in intersex patients with Y chromosome. Am J Obstect Gynecol 1976;124:293-300.

7. Michala L, Goswami D, Creighton Sm, et al. Swyer syndrome: Presentation and outcomes. BJOG 2008;115(6):737-41.

\section{ABOUT THE AUTHORS}

\section{Badekai Poornima Ramachandra Bhat (Corresponding Author)}

Associate Professor, Department of Obstetrics and Gynecology Father Muller Medical College, Mangalore-565002, Karnataka India, Phone: 9448953435, e-mail: bprbhat@refiffmail.com

\section{H Mahesha Navada}

Assistant Professor, Department of Obstetrics and Gynecology Father Muller Medical College, Mangalore-565002, Karnataka, India 